\title{
T-18, a stemonamide synthetic intermediate inhibits Pim kinase activity and induces cell apoptosis, acting as a potent anticancer drug
}

\author{
ZHEN WANG $^{1,2^{*}}$, XING-MIN LI $^{3 *}$, KUN SHANG $^{1,2}$, PENG ZHANG ${ }^{4}$, \\ CHAO-FU WANG ${ }^{1,2}$, YU-HU XIN ${ }^{1,2}$, LU ZHOU $^{4}$ and YING-YI LI ${ }^{1,2,5}$ \\ ${ }^{1}$ Cancer Research Institute, Fudan University Shanghai Cancer Center; ${ }^{2}$ Department of Oncology, \\ Shanghai Medical College, Fudan University, Shanghai; ${ }^{3}$ Community Health Service Management Center, \\ Yuhong District, Shengyang, Liaoning; ${ }^{4}$ Department of Medicinal Chemistry, School of Pharmacy, Fudan University, \\ Shanghai, P.R. China; ${ }^{5}$ Division of Molecular Bioregulation, Cancer Microenvironment Research Program, \\ Cancer Research Institute, Kanazawa University, Kanazawa, Japan
}

Received September 16, 2012; Accepted December 10, 2012

DOI: $10.3892 / o r .2013 .2233$

\begin{abstract}
Pim-3 kinase has been shown to be aberrantly expressed in premalignant and malignant lesions of endoderm-derived organs such as the liver, pancreas, colon and stomach. Pim-3 kinase inactivates the Bad protein, a proapoptotic molecule, and improves the expression of Bcl-xL, an antiapoptotic molecule, to promote cell proliferation. Thus, blocking Pim-3 kinase activity may be a new strategy for the treatment of pancreatic cancer. In this study, we screened low molecular compounds and observed that the stemonamide synthetic intermediate, T-18, potently inhibited Pim kinase activity. Moreover, T-18 inhibited the proliferation of human pancreatic, as well as that of hepatocellular and colon cancer cells in vitro. It also induced the apoptosis of human pancreatic carcinoma cells in vitro by decreasing the levels of phospho-Ser ${ }^{112}$-Bad; the levels of Pim-3 kinase and total Bad protein were not altered. Furthermore, T-18 inhibited the growth of human pancreatic cancer cells in nude mice without apparent adverse effects when the tumor was palpable. These observations indicate that stemonamide synthetic intermediates may be novel drugs for the treatment of gastrointestinal cancers, particularly pancreatic cancer.
\end{abstract}

Correspondence to: Professor Ying-Yi Li, Cancer Research Institute, Fudan University Shanghai Cancer Center, Room 1216, 2nd Building, 270 DongAn Road, Shanghai 200032, P.R. China

E-mail: liyingyi@fudan.edu.cn

${ }^{*}$ Contributed equally

Key words: Pim kinase, stemonamide synthetic intermediate, apoptosis, anticancer drug

\section{Introduction}

Pancreatic cancer is one of the common malignant tumors in Western countries with the highest incidence rate, and is also one of the cancers with the highest mortality rate (1). The characteristics of pancreatic cancer include high-grade malignancy, specific biological behavior, non-specific symptoms and tendency for early metastasis, insensitivity to chemotherapy and radiotherapy and a low rate of surgical resection (2). Compared with other cancers, the survival rate is so low that the incidence rate is basically equal to the mortality rate (3). Thus, molecular targeted therapy may be the most effective treatment for pancreatic cancer.

The proto-oncogene Pim family exhibits serine/threonine kinase activity. In humans, the Pim family includes 3 members: Pim-1, Pim-2 and Pim-3 (4). Crystal structures of Pim family kinases have revealed that the ATP-binding sites of Pim family kinases share high structural homology (5-7). The overexpression of Pim-1 and Pim-2 has been found in a variety of human hematopoietic malignancies (8-11), such as leukemia and lymphoma and some solid tumors, such as prostate cancer (12-14). Pim-3 has mainly been found in solid tumors, particularly endoderm-derived organs such as the liver, stomach, pancreas and colon (15-17) and Pim kinases have been demonstrated to inhibit apoptosis by phosphorylating the pro-apoptotic molecule, Bad at Ser ${ }^{12}$. Thus, Pim-3 may be an effective target for the treatment of cancer of endodermderived organs, particularly the pancreas (18-21). Several Pim kinase inhibitors have been reported $(22,23)$, but only a few of them are effective against all Pim family kinases (24-27). This prompted us to develop a specific inhibitor for each Pim kinase.

In this study, we investigated whether T-18, a stemonamide synthetic intermediate, may be used as a Pim-3 kinase inhibitor. T-18 reduced the levels of phosphorylated $\mathrm{Bad}$ at $\mathrm{Ser}^{112}$, resulting in the decreased growth of pancreatic carcinoma cells in vitro and the induction of apoptosis. Furthermore, T-18 also inhibited the growth of human pancreatic cancer cells in 
nude mice even when the forming tumor was observed. These results indicate that T-18 may be a lead compound that can be modified to exert a more potent inhibitory effect on Pim-3 kinase, and may thus be effectively used in the treatment of cancers with an aberrant Pim-3 overexpression.

\section{Materials and methods}

Cell culture and antibodies. The human pancreatic cancer cell lines, PCI35 (28), PCI55 (28), PCI66 (28), PANC-1 (29) and MIA PaCa-2 (30), and the human colon cancer cell line, SW480 (31), were cultured in RPMI-1640 medium, while another human pancreatic cancer cell line, L3.6pl (32), and the human colon cancer cell line, SW48 (31), were maintained in minimum essential medium. The human colon cancer cell lines, HCT29 (33) and HCT116 (34), were cultured in McCoy's 5A medium and the human hepatocarcinoma cell lines, HepG2, Hep3B (35) and HuH7 (36), were maintained in Dulbecco's modified Eagle's medium. All media were supplemented with $10 \% \mathrm{FBS}, 50 \mathrm{U} / \mathrm{ml}$ of penicillin and $50 \mathrm{U} / \mathrm{ml}$ of streptomycin. The following antibodies were used: mouse anti-human Bad (Santa Cruz Biotechnology, Santa Cruz, CA, USA), rabbit antiphosphorylated (p-) Ser ${ }^{112}$-Bad (Cell Signaling Technology, Beverly, MA, USA) and anti- $\beta$-actin antibodies (Sigma-Aldrich). The rabbit anti-human Pim-3 antibodies were prepared as previously described (16).

Preparation of stemonamide synthetic intermediates. The stemonamide synthetic intermediates were synthesized as previously described (37). T-10 and T-18 were dissolved in DMSO (Sigma-Aldrich) at the concentration of $100 \mathrm{mM}$ as stocking solution and the solutions were stable within 1 week. T-18 was dissolved in DMSO at the concentration of $100 \mathrm{mg} / \mathrm{ml}$ and the solution was diluted with olive oil to reduce the final DMSO concentration to $4 \% \mathrm{v} / \mathrm{v}$ for the animal experiment.

In vitro Pim kinase assay and Akt kinase assay. Based on the ability of Pim kinases to phosphorylate Bad at $\mathrm{Ser}^{112}$, in vitro kinase assay for Pim-1, Pim-2 and Pim-3 was established and conducted as previously described $(38,39)$. The $\mathrm{IC}_{50}$ values were calculated using logistic regression.

Akt kinase activities were determined based on their capacity to phosphorylate Bad at $\operatorname{Ser}^{136}$ as described previously (38,39). Either recombinant Akt-1 (10 ng) (Cell Signaling Technology) or Akt-2 (10 ng) (Assay Designs, Ann Arbor, MI, USA) was used as the source of the enzymes. Akt-1/2 kinase inhibitor (Sigma-Aldrich) was used as the positive control inhibitor.

Cell viability assay. Cells were inoculated into 96-multiwell plate at 3,000 cells $/ 100 \mu \mathrm{l}$ per well and incubated at $37^{\circ} \mathrm{C}$ for $18 \mathrm{~h}$. The chemicals were then added to each well at the indicated concentrations and the cells were incubated for the indicated periods of time. After removing the supernatants, the medium containing CCK-8 (Dojin Chemicals, Kumamoto, Japan) was added to each well followed by a 2-h incubation. Subsequently, the optical density was measured at $450 \mathrm{~nm}$. The number of viable cells at day 0 was regarded as the control to determine the ratios of viable cell numbers. Logistic regression was used to calculate the $\mathrm{IC}_{50}$ values.
Cell apoptosis assay. The cell apoptosis assay was operated according to the instruction manual of human Annexin V-FITC apoptosis kit (Bender MedSystems GmbH, Vienna, Austria). The cells were harvested after exposure to the chemicals and 20,000 stained cells were acquired for the analysis on the FACSCalibur system (BD Biosciences).

Western blot analysis. The L3.6pl or MIA PaCa-2 cells ( $2 \times 10^{6}$ cells) were seeded in $100-\mathrm{mm}$ culture plates. After an 18-h incubation, the chemicals were added to the plate at the final concentration of $10 \mu \mathrm{M}$. Subsequently, $60 \mu \mathrm{l}$ CellLytic ${ }^{\mathrm{TM}}$ Cell Lysis Reagent (Sigma-Aldrich) with Complete Proteinase Inhibitor Cocktail (Roche Diagnostics AG, Rotkreutz, Switzerland) was added followed by ultrasound sonication after treatment with the chemicals. Following centrifugation, the supernatants were collected for western blot analysis using the antibodies mentioned above.

Animal experiments. L3.6pl cells were suspended in HBSS at the concentration of $5 \times 10^{6}$ cells $/ \mathrm{ml}$ and $100 \mu \mathrm{l}$ cell suspensions were inoculated subcutaneously into the back of BALB/c nu/nu mice (SLC, Shizuoka, Japan). Twelve days after tumor injection, the chemical $(20 \mathrm{mg} / \mathrm{kg})$ or olive oil vehicle was injected intraperitoneally once a day for 5 days as one course. The course was repeated 3 times with an interval of 2 days. Tumor sizes were measured every 3-4 days with a caliper and tumor volumes were determined using the following the formula: tumor volume $\left(\mathrm{mm}^{3}\right)=$ (the longest diameter) $(\mathrm{mm}) \times($ the shortest diameter $)^{2}(\mathrm{~mm}) / 2$. On day 32 after the tumor cell injection, blood was taken simultaneously at tumor removal. Serum levels of alanine aminotransferase (ALT) were measured using the Fuji Drichem 5500V analyzer (Fujifilm Medical Systems, Tokyo, Japan).

Statistical analysis. Data are expressed as the means \pm SD unless otherwise indicated. One-way ANOVA and the TukeyKramer test were employed to analyze the differences between groups and a value of $\mathrm{P}<0.05$ was considered to indicate a statistically significant difference.

\section{Results}

Effects of T-18 on Pim kinase activity. We previously reported that some synthetic intermediates of stemonamide (T-2) can inhibit the activity of Pim-3 kinase in vitro (38). However, the $\mathrm{IC}_{50}$ of T-2 was at a micromolar concentration, which prompted us to find additional chemicals which can exert a more profound inhibitory effect at low doses. T-18 was synthesized based on $\mathrm{T}-2$. We found that $\mathrm{T}-18$, one of the stemonamide synthetic intermediates (Fig. 1A), inhibited Pim kinase activity (Fig. 1B). Compared with T-10 (38), T-18 inhibited Pim kinase activity to a lower extent. Moreover, T-18 inhibited Pim-1 and Pim-2 kinase activity to a similar extent as Pim-3 (Table I). We then examined the effects of T-18 on the human Akt/protein kinase B (PKB) protein kinase, another serine/threonine kinase which can phosphorylate a similar set of proteins, such as $\operatorname{Bad}(40,41)$. Akt-1/2, a specific inhibitor of Akt-1 and Akt-2, was used in our study as the positive control for a comparison against T-18 (Table I). Akt-1/2 efficiently inhibited Akt-1 and Akt-2 activity, while T-18 did not exert any effect on the Akt protein kinase. 
A

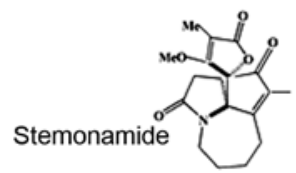

B

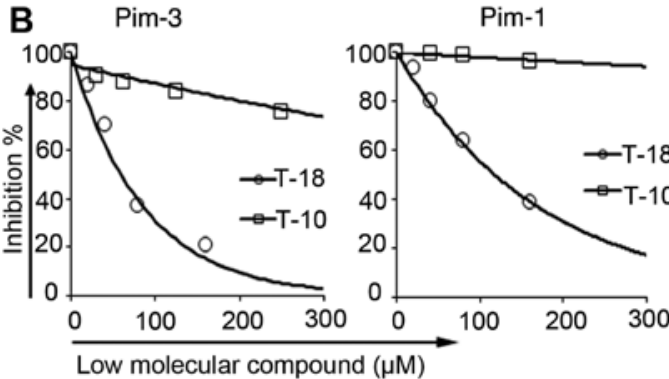

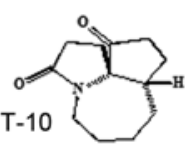
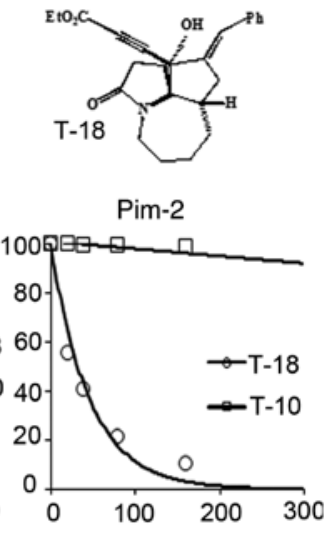

Figure 1. Structure of T-18 and its effects on Pim kinase activity. (A) Structure of stemonamides, T-10 and T-18. (B) Effects of T-10 and T-18 on Pim kinase activity.
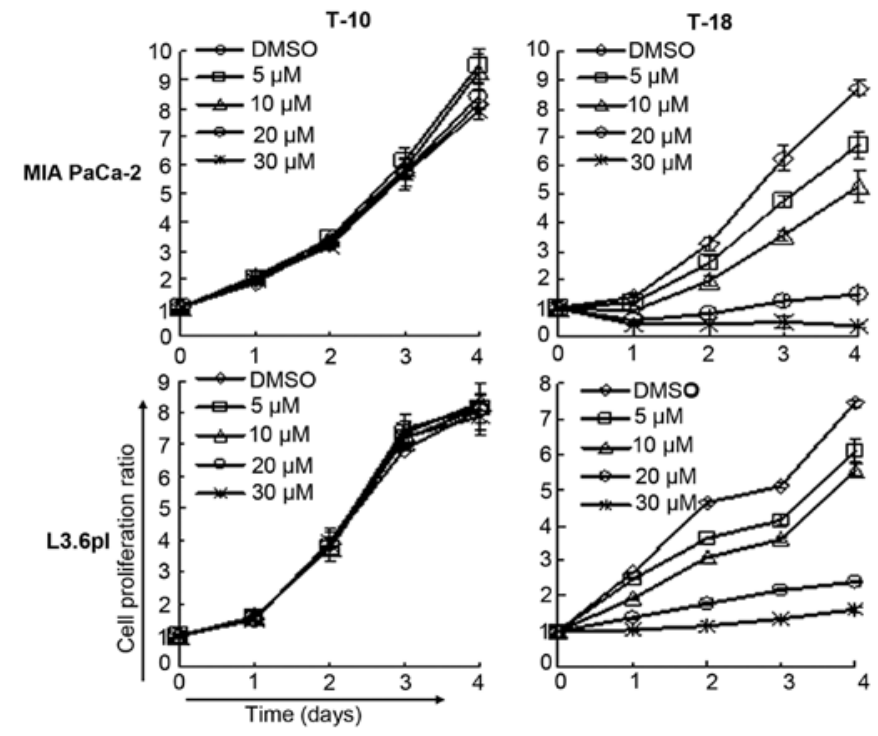

Figure 2. Inhibitory effects of T-18 on cell proliferation of human pancreatic cancer cells in vitro. Cell numbers were determined in MIA PaCa-2 and L3.6pl cells treated with the indicated concentrations of T-18 and T-10 as described in Materials and methods. The cell numbers were determined daily for 4 days with the use of CCK- 8 assay and the ratios to day 0 were calculated. Results are expressed as the means \pm SD $(n=5)$. Similar experiments were repeated 3 times, and representative results from 3 independent experiments are shown.

Thus, T-18 can potently and selectively inhibit Pim-3 kinase activity, but not that of Akt.

Effects of T-18 on cell proliferation in vitro. Two human pancreatic cancer cell lines, MIA PaCa- 2 and L3.6pl, were recruited to examine the effects of $\mathrm{T}-18$ on cell proliferation in vitro (Fig. 2). The results showed that T-18 effectively inhibited cell proliferation in a dose-dependent manner. However, T-10 had little effect on the cell proliferation of these cancer cell lines, and had little influence on Pim-3 kinase activity. T-18 was added to the medium of the other human pancreatic cancer cell lines (PCI66, PCI35, PCI55 and PANC-1), hepatocellular carcinoma cell lines (HuH7, HepG2 and Hep3B) and colon cancer cell lines (SW480, SW48, HT29 and HCT116) to determine
Table I. Inhibitory activity of T-18 on Pim and Akt kinases.

\begin{tabular}{lccccc}
\hline & \multicolumn{5}{c}{$\mathrm{IC}_{50}(\mu \mathrm{mol} / \mathrm{l})$} \\
\cline { 2 - 6 } Chemical & Pim-3 & Pim-1 & Pim-2 & Akt-1 & Akt-2 \\
name & & & & & \\
\hline T-10 & $>2,000$ & $>2,000$ & $>2,000$ & $>2,000$ & $>2,000$ \\
T-18 & 57 & 118 & 27 & $>2,000$ & $>2,000$ \\
Akt-1/2 & ND & ND & ND & 31.6 & 72.5 \\
\hline
\end{tabular}

Inhibitory effects were investigated up to T-18 concentrations of $320 \mu \mathrm{mol} / 1$ and $\mathrm{IC}_{50}$ values were calculated. ND, not determined.

the effect of T-18 on the proliferation of these cells (Table II). Almost all the cancer cell lines were sensitive to T-18. These observations suggest that T-18 inhibits Pim-3 kinase activity and has an effect on the proliferation of these cells.

Effects of T-18 on cell apoptosis. In our previous studies, we demonstrated that a Pim-3 shRNA-mediated reduction in Pim-3 protein expression decreased the levels of phospho-Ser ${ }^{112}$ Bad and increased the number of apoptotic cells in human pancreatic and colon cancer cell lines $(16,17)$. In this study, we investigated whether T-18 can affect the phosphorylation state of $\mathrm{Bad}$ in the human pancreatic cancer cell lines, MIA PaCa-2 and L3.6pl. Consistent with our previous results, the levels of phospho-Ser ${ }^{12}$-Bad decreased in the cell lines following treatment with T-18. However, the levels of Pim-3 kinase protein or total Bad protein were not altered with the treatment time (Fig. 3). Moreover, early apoptotic and late apoptotic cells were enhanced in both cell lines (Fig. 4) following treatment with T-18 for 24 and $48 \mathrm{~h}$. These observations indicate that T-18 prevents the phosphorylation of Bad, eventually leading to apoptosis in human pancreatic cancer cells.

Effects of T-18 on tumor growth in vivo. Finally, we investigated the effects of T-18 on tumor growth in vivo. We subcutaneously injected L3.6pl pancreatic cancer cells into nude mice as 


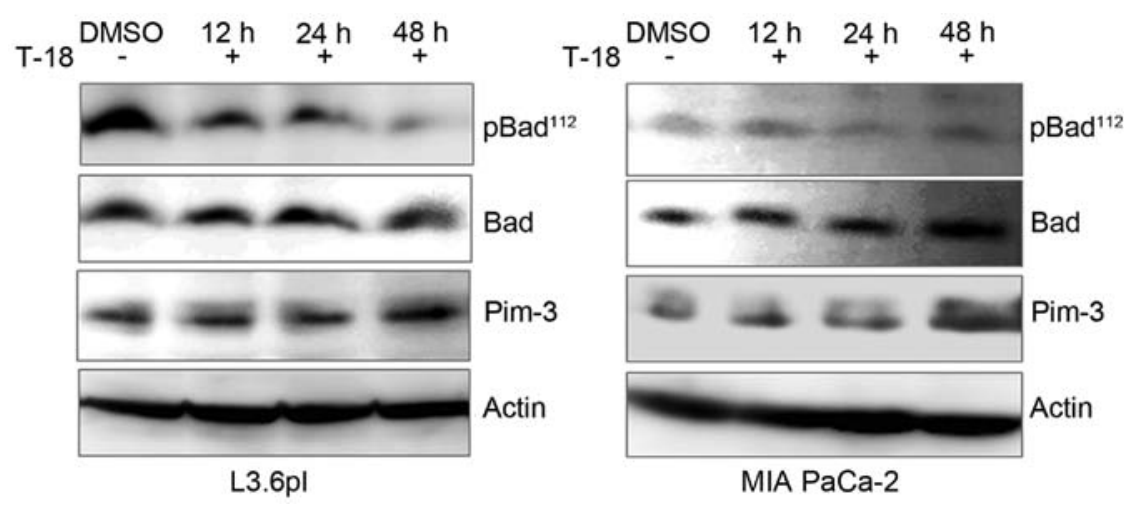

Figure 3. Effects of T-18 on the phosphorylation state of Bad at Ser ${ }^{12}$ in human pancreatic cancer cell lines. Cell lysates were obtained from L3.6pl and MIA PaCa-2 cells treated with DMSO or T-18 $(4 \mu \mathrm{M})$ for the indicated periods of time and subjected to western blot analysis as described in Materials and methods. Representative results from 3 independent experiments are shown.

Table II. Effects of T-18 on the proliferation of human cancer cells in vitro.

\begin{tabular}{llc}
\hline \multirow{2}{*}{ Cell type } & Cell line name & $\begin{array}{c}\text { Proliferation } \mathrm{IC}_{50}(\mu \mathrm{mol} / \mathrm{l}) \\
\text { T-18 }\end{array}$ \\
\hline Pancreas & L3.6pl & 3.46 \\
& MIA PaCa-2 & 2.09 \\
& PCI66 & 2.24 \\
& PCI35 & 2.25 \\
& PCI55 & 3.31 \\
& PANC-1 & 2.96 \\
Liver & HuH7 & 5.25 \\
& HepG2 & 21.4 \\
Colon & Hep3B & - \\
& SW480 & 1.78 \\
& SW48 & 2.75 \\
& HT29 & 4.32 \\
& HCT116 & 1.79 \\
\hline
\end{tabular}

Data represent the means \pm SD calculated from 3 independent experiments.

described above and T-18 treatment commenced on day 12 after the tumor injection, when the tumor was palpable (Fig. 5A). The tumors of the mice in the vehicle-treated group grew more rapidly than those of the mice in the T-18-treated group (Fig. 5B). During the course of the experiment, all mice tolerated T-18 well, as evidenced by the fact that no body weight loss was observed (Fig. 5C) and the changes in serum ALT levels (Fig. 5D). These results suggest that T-18 suppresses tumor growth in vivo without any significant side-effects.

\section{Discussion}

Pancreatic cancer is a malignant tumor of the pancreas, and poses a threat to human health. The majority of patients are diagnosed at an advanced stage, thus surgical treatment is not valid and the only treatment options are radiotherapy or chemotherapy, with the survival time being less than a year $(42,43)$. Thus, molecular targeted therapy is considered to be a very promising treatment. These targeted molecules are not expressed in normal tissues but are aberrantly expressed in tumor tissues and play a key role in regulating tumor cell proliferation. The Pim-3 kinase is aberrantly expressed in premalignant and malignant lesions of endoderm-derived organs, such as the liver, pancreas, colon and stomach $(16,17,44,45)$ but not in normal tissues. The Pim-3 kinase inactivates the Bad protein by phosphorylating Bad at Ser ${ }^{112}$ to promote cell proliferation (25), providing the characteristics of a targeted molecule. Thus, blocking Pim-3 kinase activity may be a new strategy for the treatment of pancreatic cancer.

The crystal structure of Pim-1 and Pim-2 reveals that there is a special hinge region that can connect the 2 lobes of the protein kinase domain, which presents a unique way for ATP to bind with Pim kinases instead of other protein kinases $(5,46,47)$. Thus, it may be possible to develop an inhibitor that selectively targets Pim kinases, not other seine/threonine kinases (48). Existing small molecule inhibitors against Pim kinases that have been reported include flavonol quercetargetin (7), imidazole[1,2-b]pyridazines $(26,49)$, bezylindene-thiazolidine2,4-dione (50-52), 3,5-disubstituted indole derivatives (53), pyrazolo[3,4-g]quinoxaline derivatives (54) and $\mathrm{N}-10$ substituted pyrrolo[2,3-a]carbazole derivatives (55-57). These molecules have been certified to inhibit the proliferation of human cancer cells in vitro and/or in vivo. However, most of the compounds are multi-Pim kinase inhibitors and Pim-3 has received the least attention among the Pim family kinases. Thus, a novel and safe Pim-3 targeting inhibitor is required. We have previously demonstrated that other stemonamide synthetic intermediates (T-2, T-5) can inhibit Pim kinases activity and suppress cancer cell proliferation in vitro, as well as tumor growth in vivo (38). However, the $\mathrm{IC}_{50}$ of $\mathrm{T}-2$ was at a micromolar concentration. In this study, we investigated another low molecular compound (T-18) that shares homoplastic structure with T-2 and may exert a more effective anticancer effect.

To recognize a Pim-3 inhibitor, a series of low molecule chemicals were screened and a stemonamide synthetic intermediate, T-18, was observed, which was similar to T-2 which was investigated in our previous study (38). In the current study, T-18 inhibited the activity of Pim-3, Pim-1 and Pim-2 

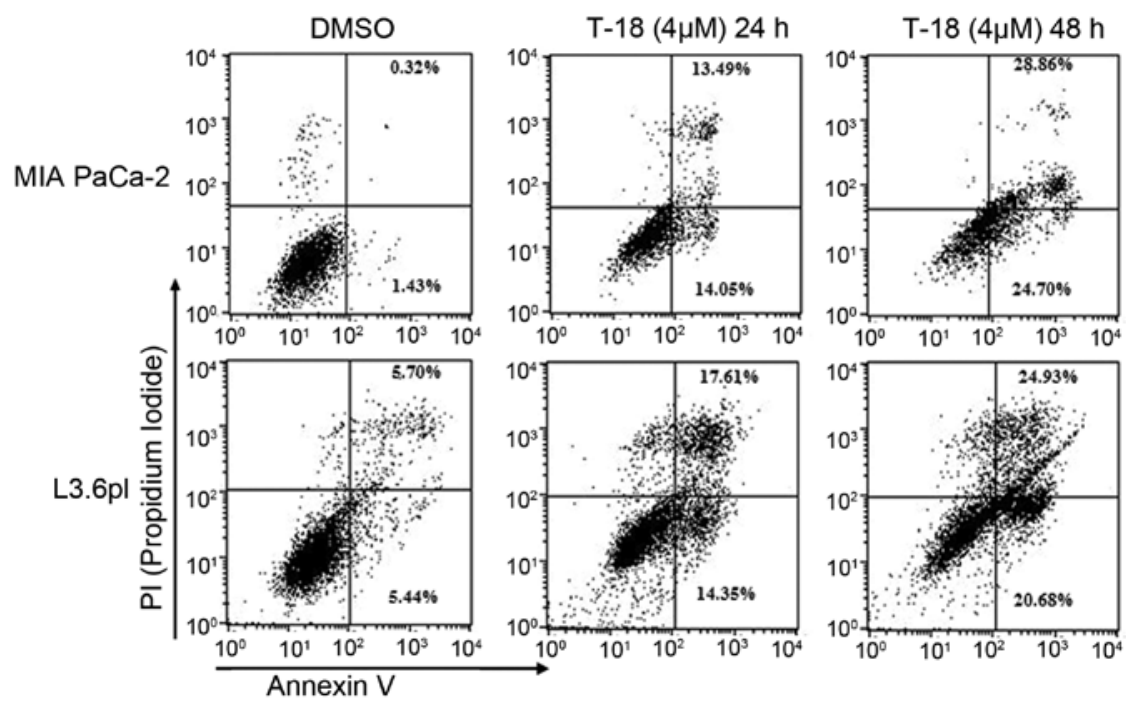

Figure 4. Effects of T-18 on cell apoptosis in vitro. Cells were harvested 24 or $48 \mathrm{~h}$ after treatment and were then stained with Annexin V and PI as described in Materials and methods. The number in each quadrant indicates the proportion of cells present in the quadrant. Representative results from 3 independent experiments are shown.

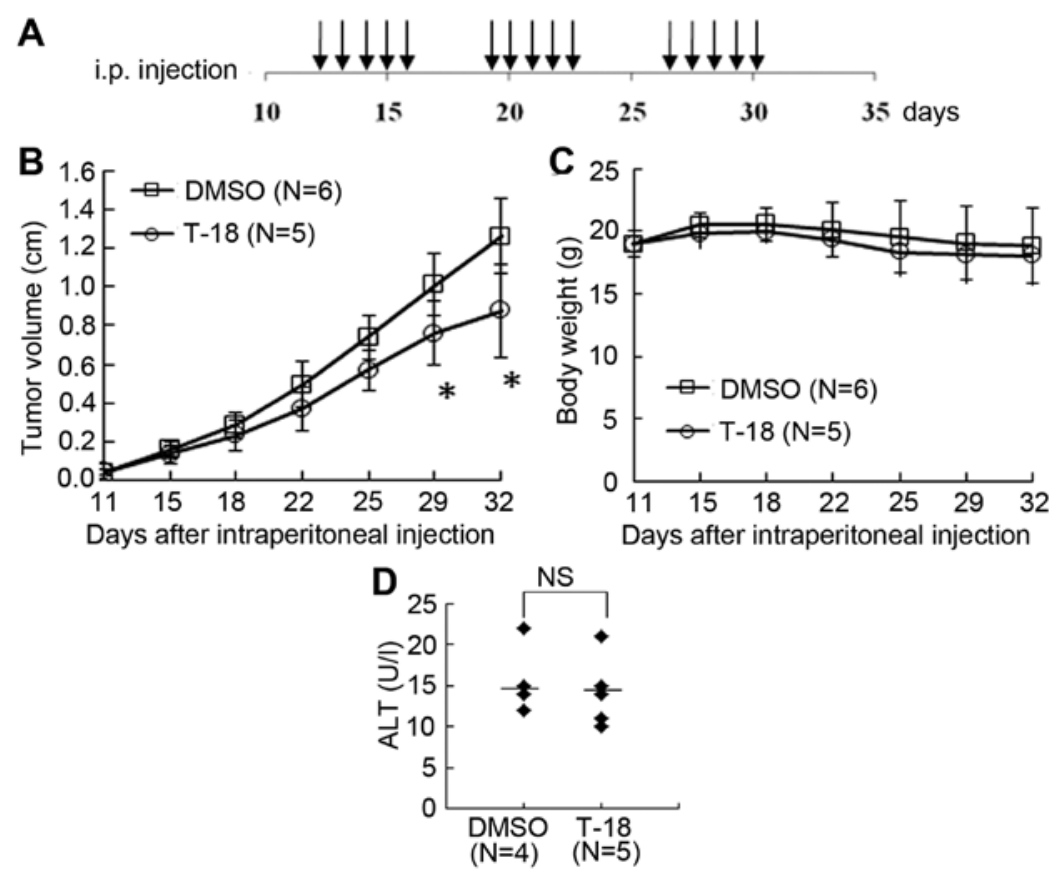

Figure 5. Effects of T-18 on tumor growth in vivo. (A) Schematic overview of the mouse experiment. L3.6pl pancreatic cancer cells were subcutaneously injected into nude mice and T-18 treatment commenced on day 12 after the tumor injection when the tumor was palpable. The arrows indicate the days when T-18 treatment was administered. (B) Tumor sizes were measured twice a week. Data represent the means \pm SEM ( $\mathrm{P}<0.05)$. (C) Body weights were measured twice a week after inoculation. Data represent the means \pm SD. (D) Serum ALT levels were determined 32 days after tumor injection.

but not that of Akt-1 or Akt-2 kinase, showing the specific inhibitory effect on Pim family kinases and not on Akt kinases. Moreover, T-18 suppressed the proliferation of human pancreatic carcinoma cells in vitro, as well as the in vivo tumor growth of human pancreatic cancer cells injected into nude mice, without any severe adverse effects. Furthermore, T-18 prevented Bad phosphorylation at $\mathrm{Ser}^{112}$, while increasing the number of apoptotic pancreatic cancer cells; however, the levels of Pim-3 protein and total Bad protein were not altered. Since Pim-1 and Pim-2 protein can phosphorylate Bad at
Ser ${ }^{112}$, which were not found in human pancreatic cancer cells (unpublished data), Pim-3 kinase was regarded as the target of T-18. T-18 inhibited Pim-3 activity, inactivating Bad and finally inducing apoptosis.

As we have previously demonstrated, T-2 (38), similar to T-18, can inhibit Pim-3 activity and reduce the growth of pancreatic cancer cells in vitro and in vivo. T-2 also inhibited in vivo tumor growth effectively. However, as shown in this study, T-18 inhibited the proliferation of human cancer cells in vitro with a lower $\mathrm{IC}_{50}$ value. Perhaps T-18 is an ideal compound that can 
be modified to exert a more potent inhibitory effect without any severe side-effects.

Another serine/threonine kinase, namely Akt, can phosphorylate similar sets of substrates, such as Bad, as Pim kinases, thus initiating the proliferation of cancer cells (41). Akt is aberrantly activated in various types of tumors and Akt inhibitors have been extensively investigated (40). Although the Akt inhibitor, GSK690693, has exhibited potent antitumor activity in pre-clinical animal experiments (41), the genetic disruption of each Akt kinase gene results in severe phenotypic changes, such as neonatal mortality, severe growth retardation and reduced brain size (58-60) and Akt-2 inhibition induces severe hyperglycemia (41). This is a serious impediment for the clinical use of Akt inhibitors in anticancer treatment. The Pim-3 kinase is aberrantly expressed in malignant lesions but not in endoderm-derived normal tissues, such as the liver, pancreas, colon and stomach $(16,17,44,45)$ and promotes tumor development. Moreover, Pim-3 gene deficiency does not induce apparent phenotypic changes, suggesting that Pim-3 may be physiologically dispensable (61). Pim kinases are not localized downstream of the insulin receptor signaling pathway but the Akt kinase is. The inhibition of Pim kinases has few effects on normal metabolism. Thus, Pim kinases may be more effective targets compared to Akt in the molecular targeted therapy of various types of cancer, particularly pancreatic cancer, exerting potent effects and few adverse effects. In this study, we showed that T-18 inhibited Pim kinases activity but failed to suppress Akt-1 and Akt-2 activity, suggesting that T-18 may be a safe drug for use in molecular targeted therapy. However, it may be difficult to discovery a specific inhibitor against either Pim-1 or Pim-3 kinase due to their extraordinarily similar peptide substrate identity (46). It would be of interest to determine whether a specific inhibitor against anyone of the Pim family kinases will prove to be advantageous over existing Pim kinase inhibitors.

\section{Acknowledgements}

The authors gratefully acknowledge grant support from The National Science Foundation of China (NSFC) (30973476), the Shanghai Pujiang Program (KW201028464), Fudan University '985 Project' Phase III Cancer Research Projects II (985III-YFX0102), 'Start Up' Project of the Shanghai Cancer Center (YJRC0901), and Shanghai Committee of Science and Technology (12DZ2260100). The authors thank Professor Hiroyuki Ishibashi of School of Pharmaceutical Sciences, Kanazawa University, for providing T-18 and T-10.

\section{References}

1. Aune D, Vieira AR, Chan DS, et al: Height and pancreatic cancer risk: a systematic review and meta-analysis of cohort studies. Cancer Causes Control 23: 1213-1222, 2012.

2. Li D, Xie K, Wolff R and Abbruzzese JL: Pancreatic cancer. Lancet 363: 1049-1057, 2004.

3. Hochster HS, Haller DG, de Gramont A, et al: Consensus report of the international society of gastrointestinal oncology on therapeutic progress in advanced pancreatic cancer. Cancer 107: 676-685, 2006

4. Mikkers H, Allen J, Knipscheer P, et al: High-throughput retroviral tagging to identify components of specific signaling pathways in cancer. Nat Genet 32: 153-159, 2002.

5. Qian KC, Wang L, Hickey ER, et al: Structural basis of constitutive activity and a unique nucleotide binding mode of human Pim-1 kinase. J Biol Chem 280: 6130-6137, 2005.
6. Kumar A, Mandiyan V, Suzuki Y, et al: Crystal structures of proto-oncogene kinase Pim1: a target of aberrant somatic hypermutations in diffuse large cell lymphoma. J Mol Biol 348: 183-193, 2005.

7. Holder S, Zemskova M, Zhang C, et al: Characterization of a potent and selective small-molecule inhibitor of the PIM1 kinase. Mol Cancer Ther 6: 163-172, 2007.

8. Alvarado Y, Giles FJ and Swords RT: The PIM kinases in hematological cancers. Expert Rev Hematol 5: 81-96, 2012.

9. Kim KT, Baird K, Ahn JY, et al: Pim-1 is up-regulated by constitutively activated FLT3 and plays a role in FLT3-mediated cell survival. Blood 105: 1759-1767, 2005.

10. Pasqualucci L, Neumeister P, Goossens T, et al: Hypermutation of multiple proto-oncogenes in B-cell diffuse large-cell lymphomas. Nature 412: 341-346, 2001.

11. Gaidano G, Pasqualucci L, Capello D, et al: Aberrant somatic hypermutation in multiple subtypes of AIDS-associated nonHodgkin lymphoma. Blood 102: 1833-1841, 2003.

12. Dhanasekaran SM, Barrette TR, Ghosh D, et al: Delineation of prognostic biomarkers in prostate cancer. Nature 412: 822-826, 2001.

13. Valdman A, Fang X, Pang ST, Ekman P and Egevad L: Pim-1 expression in prostatic intraepithelial neoplasia and human prostate cancer. Prostate 60: 367-371, 2004.

14. Xu Y, Zhang T, Tang H, et al: Overexpression of PIM-1 is a potential biomarker in prostate carcinoma. J Surg Oncol 92: 326-330, 2005.

15. Liu LM, Zhang JX, Wang XP, Guo HX, Deng H and Luo J: Pim-3 protects against hepatic failure in D-galactosamine (D-GalN)sensitized rats. Eur J Clin Invest 40: 127-138, 2010.

16. Li YY, Popivanova BK, Nagai Y, Ishikura H, Fujii C and Mukaida N: Pim-3, a proto-oncogene with serine/threonine kinase activity, is aberrantly expressed in human pancreatic cancer and phosphorylates Bad to block Bad-mediated apoptosis in human pancreatic cancer cell lines. Cancer Res 66: 6741-6747, 2006.

17. Popivanova BK, Li YY, Zheng H, et al: Proto-oncogene, Pim-3 with serine/threonine kinase activity, is aberrantly expressed in human colon cancer cells and can prevent Bad-mediated apoptosis. Cancer Sci 98: 321-328, 2007.

18. Lilly M, Sandholm J, Cooper JJ, Koskinen PJ and Kraft A: The PIM-1 serine kinase prolongs survival and inhibits apoptosis-related mitochondrial dysfunction in part through a bcl-2-dependent pathway. Oncogene 18: 4022-4031, 1999.

19. Fox CJ, Hammerman PS, Cinalli RM, Master SR, Chodosh LA and Thompson CB: The serine/threonine kinase Pim-2 is a transcriptionally regulated apoptotic inhibitor. Genes Dev 17: 1841-1854, 2003.

20. Yan B, Zemskova M, Holder S, et al: The PIM-2 kinase phosphorylates BAD on serine 112 and reverses BAD-induced cell death. J Biol Chem 278: 45358-45367, 2003.

21. Macdonald A, Campbell DG, Toth R, McLauchlan H, Hastie CJ and Arthur JS: Pim kinases phosphorylate multiple sites on Bad and promote 14-3-3 binding and dissociation from Bcl-XL. BMC Cell Biol 7: 1, 2006.

22. Brault L, Gasser C, Bracher F, Huber K, Knapp S and Schwaller J: PIM serine/threonine kinases in the pathogenesis and therapy of hematologic malignancies and solid cancers. Haematologica 95: 1004-1015, 2010.

23. Anizon F, Shtil AA, Danilenko VN and Moreau P: Fighting tumor cell survival: advances in the design and evaluation of Pim inhibitors. Curr Med Chem 17: 4114-4133, 2010.

24. Akue-Gedu R, Rossignol E, Azzaro S, et al: Synthesis, kinase inhibitory potencies, and in vitro antiproliferative evaluation of new Pim kinase inhibitors. J Med Chem 52: 6369-6381, 2009.

25. Tao ZF, Hasvold LA, Leverson JD, et al: Discovery of $3 \mathrm{H}$-benzo[4,5]thieno[3,2-d]pyrimidin-4-ones as potent, highly selective, and orally bioavailable inhibitors of the human protooncogene proviral insertion site in moloney murine leukemia virus (PIM) kinases. J Med Chem 52: 6621-6636, 2009.

26. Chen LS, Redkar S, Bearss D, Wierda WG and Gandhi V: Pim kinase inhibitor, SGI-1776, induces apoptosis in chronic lymphocytic leukemia cells. Blood 114: 4150-4157, 2009.

27. Mumenthaler SM, Ng PY, Hodge A, et al: Pharmacologic inhibition of Pim kinases alters prostate cancer cell growth and resensitizes chemoresistant cells to taxanes. Mol Cancer Ther 8: 2882-2893, 2009.

28. Yano T, Ishikura H, Kato H, Ogawa Y, Kondo S and Yoshiki T: Vaccination effect of interleukin-6-producing pancreatic cancer cells in nude mice: a model of tumor prevention and treatment in immune-compromised patients. Jpn J Cancer Res 92: 83-87, 2001. 
29. Lieber M, Mazzetta J, Nelson-Rees W, Kaplan M and Todaro G: Establishment of a continuous tumor-cell line (panc-1) from a human carcinoma of the exocrine pancreas. Int J Cancer 15 : 741-747, 1975.

30. Yunis AA, Arimura GK and Russin DJ: Human pancreatic carcinoma (MIA PaCa-2) in continuous culture: sensitivity to asparaginase. Int J Cancer 19: 128-135, 1977.

31. Leibovitz A, Stinson JC, McCombs WB III, McCoy CE, Mazur KC and Mabry ND: Classification of human colorectal adenocarcinoma cell lines. Cancer Res 36: 4562-4569, 1976.

32. Bruns CJ, Harbison MT, Kuniyasu H, Eue I and Fidler IJ: In vivo selection and characterization of metastatic variants from human pancreatic adenocarcinoma by using orthotopic implantation in nude mice. Neoplasia 1: 50-62, 1999.

33. Marshall CJ, Franks LM and Carbonell AW: Markers of neoplastic transformation in epithelial cell lines derived from human carcinomas. J Natl Cancer Inst 58: 1743-1751, 1977.

34. Brattain MG, Brattain DE, Fine WD, et al: Initiation and characterization of cultures of human colonic carcinoma with different biological characteristics utilizing feeder layers of confluent fibroblasts. Oncodev Biol Med 2: 355-366, 1981

35. Knowles BB, Howe CC and Aden DP: Human hepatocellular carcinoma cell lines secrete the major plasma proteins and hepatitis B surface antigen. Science 209: 497-499, 1980.

36. Nakabayashi H, Taketa K, Miyano K, Yamane T and Sato J Growth of human hepatoma cells lines with differentiated functions in chemically defined medium. Cancer Res 42 : 3858-3863, 1982

37. Taniguchi T, Tanabe $\mathrm{G}$, Muraoka $\mathrm{O}$ and Ishibashi $\mathrm{H}$ : Total synthesis of (+/-)-stemonamide and (+/-)-isostemonamide using a radical cascade. Org Lett 10: 197-199, 2008.

38. Li YY, Wang YY, Taniguchi T, et al: Identification of stemonamide synthetic intermediates as a novel potent anticancer drug with an apoptosis-inducing ability. Int J Cancer 127: 474-484, 2010.

39. Wang YY, Taniguchi T, Baba T, Li YY, Ishibashi $\mathrm{H}$ and Mukaida N: Identification of a phenanthrene derivative as a potent anticancer drug with Pim kinase inhibitory activity. Cancer Sci 103: 107-115, 2011.

40. Amaravadi $\mathrm{R}$ and Thompson CB: The survival kinases Akt and Pim as potential pharmacological targets. J Clin Invest 115 2618-2624, 2005.

41. Rhodes N, Heerding DA, Duckett DR, et al: Characterization of an Akt kinase inhibitor with potent pharmacodynamic and antitumor activity. Cancer Res 68: 2366-2374, 2008.

42. André T, Balosso J, Louvet C, et al: Adenocarcinoma of the pancreas. General characteristics. Presse Med 27: 533-536, 1998 (In French).

43. Jian J, Hu ZF and Huang Y: Effect of ginsenoside Rg3 on Pim-3 and Bad proteins in human pancreatic cancer cell line PANC-1. Ai Zheng 28: 461-465, 2009 (In Chinese).

44. Fujii C, Nakamoto Y, Lu P, et al: Aberrant expression of serine/ threonine kinase Pim-3 in hepatocellular carcinoma development and its role in the proliferation of human hepatoma cell lines. Int J Cancer 114: 209-218, 2005.

45. Zheng HC, Tsuneyama K, Takahashi H, et al: Aberrant Pim-3 expression is involved in gastric adenoma-adenocarcinoma sequence and cancer progression. J Cancer Res Clin Oncol 134: 481-488, 2008.
46. Bullock AN, Debreczeni J, Amos AL, Knapp S and Turk BE Structure and substrate specificity of the Pim-1 kinase. J Biol Chem 280: 41675-41682, 2005.

47. Bullock AN, Russo S, Amos A, et al: Crystal structure of the PIM2 kinase in complex with an organoruthenium inhibitor. PLoS One 4: e7112, 2009.

48. Swords R, Kelly K, Carew J, et al: The Pim kinases: new targets for drug development. Curr Drug Targets 12: 2059-2066, 2011.

49. Pogacic V, Bullock AN, Fedorov O, et al: Structural analysis identifies imidazo[1,2-b]pyridazines as PIM kinase inhibitors with in vitro antileukemic activity. Cancer Res 67: 6916-6924, 2007.

50. Dakin LA, Block MH, Chen H, et al: Discovery of novel benzylidene-1,3-thiazolidine-2,4-diones as potent and selective inhibitors of the PIM-1, PIM-2, and PIM-3 protein kinases. Bioorg Med Chem Lett 22: 4599-4604, 2012.

51. Xia Z, Knaak C, Ma J, et al: Synthesis and evaluation of novel inhibitors of Pim-1 and Pim-2 protein kinases. J Med Chem 52: 74-86, 2009.

52. Lin YW, Beharry ZM, Hill EG, et al: A small molecule inhibitor of Pim protein kinases blocks the growth of precursor T-cell lymphoblastic leukemia/lymphoma. Blood 115: 824-833, 2010.

53. Nishiguchi GA, Atallah G, Bellamacina C, et al: Discovery of novel 3,5-disubstituted indole derivatives as potent inhibitors of Pim-1, Pim-2, and Pim-3 protein kinases. Bioorg Med Chem Lett 21: 6366-6369, 2011.

54. Gavara L, Saugues E, Alves G, Debiton E, Anizon F and Moreau P: Synthesis and biological activities of pyrazolo[3,4-g] quinoxaline derivatives. Eur J Med Chem 45: 5520-5526, 2010.

55. Akue-Gedu R, Letribot B, Saugues E, Debiton E, Anizon F and Moreau P: Kinase inhibitory potencies and in vitro antiproliferative activities of $\mathrm{N}-10$ substituted pyrrolo[2,3-a]carbazole derivatives. Bioorg Med Chem Lett 22: 3807-3809, 2012.

56. Akue-Gedu R, Nauton L, Thery V, et al: Synthesis, Pim kinase inhibitory potencies and in vitro antiproliferative activities of diversely substituted pyrrolo[2,3-a]carbazoles. Bioorg Med Chem 18: 6865-6873, 2010.

57. Letribot B, Akue-Gedu R, Santio NM, et al: Use of copper(I) catalyzed azide alkyne cycloaddition $(\mathrm{CuAAC})$ for the preparation of conjugated pyrrolo[2,3-a]carbazole Pim kinase inhibitors. Eur J Med Chem 50: 304-310, 2012.

58. Chen WS, Xu PZ, Gottlob $\mathrm{K}$, et al: Growth retardation and increased apoptosis in mice with homozygous disruption of the Aktl gene. Genes Dev 15: 2203-2208, 2001.

59. Easton RM, Cho H, Roovers K, et al: Role for Akt3/protein kinase Bgamma in attainment of normal brain size. Mol Cell Biol 25: 1869-1878, 2005.

60. Woulfe D, Jiang H, Morgans A, Monks R, Birnbaum M and Brass LF: Defects in secretion, aggregation, and thrombus formation in platelets from mice lacking Akt2. J Clin Invest 113: 441-450, 2004.

61. Mukaida N, Wang YY and Li YY: Roles of Pim-3, a novel survival kinase, in tumorigenesis. Cancer Sci 102: 1437-1442, 2011. 